\title{
Avaliação da passagem de plantão fisioterapêutica em âmbito hospitalar
}

\author{
Evaluation of physiotherapeutic duty passage in hospital scope \\ Evaluación de pasajes de servicio fisioterapéutico en alcance hospitalario
}

Francelly Carvalho dos Santos ORCID: https://orcid.org/0000-0002-0438-4131 Universidade Federal do Piauí, Brasil

E-mail: francellycarvalhods@gmail.com

Brena Costa de Oliveira

ORCID: https://orcid.org/0000-0002-2352-6342

Universidade Federal do Piauí, Brasil

E-mail: brena_oliveira.5@hotmail.com

Whelen de Sousa Moreira

ORCID: https://orcid.org/0000-0002-8477-5174

Universidade Federal do Piauí, Brasil

E-mail: whellen_2011@ @otmail.com

Camila de Araújo Lima

ORCID: https://orcid.org/0000-0002-4144-7621 Universidade Federal do Piauí, Brasil

E-mail:kmilalima7@gmail.com

Cibelle de Sousa e Silva

ORCID: https://orcid.org/0000-0001-5715-5407 Universidade Estadual do Piauí, Brasil

E-mail: cibellycaldas@hotmail.com

Samara Martins de Oliveira Souza

ORCID: https://orcid.org/0000-0002-8088-8817

Universidade Estadual do Piaú, Brasil

E-mail: samaramartins10@hotmail.com

Letícia Graziela Lopes França

ORCID: https://orcid.org/0000-0002-9977-8933 Universidade Estadual do Piauí, Brasil

E-mail:1_graziela@hotmail.com

Thamires da Silva Leal

ORCID: https://orcid.org/0000-0002-4884-9498

Universidade Estadual do Piauí, Brasil

E-mail: thamiresleal.fisio@gmail.com

Ketlhen Ravena Rodrigues dos Santos Gonçalves

ORCID: https://orcid.org/0000-0003-2449-3826 Universidade Estadual do Piauí, Brasil E-mail: ravenarodrigues08@gmail.com

Luana Gabrielle De França Ferreira ORCID: https://orcid.org/0000-0001-6145-0505 Universidade Federal do Piauí, Brasil E-mail: luanagabrielle@yahoo.com.br

\begin{abstract}
Resumo
O termo passagem de plantão refere-se ao momento em que uma equipe de saúde transmite informações na troca de turnos de trabalho, em que ocorre a identificação do paciente, bem como do quadro clínico de cada um deles e a definição de necessidades para o planejamento e execução de medidas necessárias aos cuidados. O objetivo da pesquisa foi avaliar a forma de passagem de plantão fisioterapêutica no Hospital Universitário da Universidade Federal do Piauí (HU-UFPI). O estudo foi realizado na Unidade de Terapia Intensiva (UTI) e nos postos das enfermarias. $\mathrm{O}$ grupo de fisioterapeutas participante desta pesquisa foi composto por 23 profissionais. Foi realizada a aplicação de uma ficha para traçar o perfil da amostra, em seguida foi feita uma entrevista semiestruturada com 10 profissionais para análise qualitativa da passagem de plantão, posteriormente, foi realizado preenchimento do checklist da passagem de plantão a partir da observação da transferência de cuidados realizada pelos fisioterapeutas de cada setor. A que passagem de plantão fisioterapêutica no serviço avaliado ocorre de forma presencial, a minoria dos profissionais utiliza a ficha de passagem de plantão impressa, bem como a minoria verbaliza o nome completo do paciente no momento da passagem. Os profissionais relataram como pontos negativos as interferências causadas pelos ruídos dos setores e consideraram onerosa a impressão do instrumento, entretanto, reconheceram a importância do
\end{abstract}


momento da passagem de plantão para continuidade segura e qualificada dos cuidados, e que a ficha é um instrumento que garante a recordação de informações relevantes dos pacientes.

Palavras-chave: Passagem de plantão; Ambiente hospitalar; Fisioterapeutas.

\begin{abstract}
The term shift change refers to the moment when a health team transmits information when changing work shifts, when the patient is identified, as well as the clinical condition of each one of them and the definition of the need for planning and execution of necessary care measures. The objective of the research was to evaluate a form of physical therapy shift change at the University Hospital of the Federal University of Piauí (HU-UFPI). The study was carried out in the Intensive Care Unit (ICU) and in nursing stations. The group of physiotherapists participating in this research consisted of 23 professionals. A form was applied to outline the profile of the sample, followed by a semistructured interview with 10 professionals for a qualitative analysis of the shift change. care performed by physiotherapists in each sector. When the physical therapy shift change in the evaluated service occurs in person, a minority of professionals use the printed shift change sheet, and a minority verbalize the patient's full name at the time of the change. The professionals reported as negative points such as interference caused by the noise of the sectors and considered the printing of the instrument to be costly, however, they recognized the importance of the moment of shift change for safe and qualified continuity of care, and that the form is an instrument that guarantees the recall of relevant patient information.
\end{abstract}

Keywords: Care transfer; Hospital environment; Physiotherapists.

\title{
Resumen
}

El término cambio de turno se refiere al momento en el que un equipo de salud transmite información al cambiar de turno de trabajo, cuando se identifica al paciente, así como el estado clínico de cada uno de ellos y la definición de necesidades para la planificación e implementación de las medidas asistenciales necesarias. El objetivo de la investigación fue evaluar la forma de cambio de turno de fisioterapia en el Hospital Universitario de la Universidad Federal de Piauí (HU-UFPI). El estudio se realizó en la Unidad de Cuidados Intensivos (UCI) y en puestos de enfermería. El grupo de fisioterapeutas que participaron en esta investigación estuvo formado por 23 profesionales. Se aplicó un formulario para delinear el perfil de la muestra, seguido de una entrevista semiestructurada con 10 profesionales para un análisis cualitativo del cambio de turno. Posteriormente, se completó el checklist de cambio de turno a partir de la observación de la transferencia de turnos. realizado por fisioterapeutas en cada sector. Cuando el cambio de turno de fisioterapia en el servicio evaluado ocurre en persona, la minoría de profesionales usa la hoja impresa de cambio de turno y la minoría verbaliza el nombre completo del paciente en el momento del cambio. Los profesionales reportaron como puntos negativos la interferencia provocada por el ruido de los sectores y consideraron costosa la impresión del instrumento, sin embargo, reconocieron la importancia del momento del cambio de turno para la continuidad asistencial segura y calificada, y que la forma es un instrumento que garantiza la recuperación de información relevante del paciente.

Palabras clave: Cambio de turno; Entorno hospitalário; Fisioterapeutas.

\section{Introdução}

Em todos os setores da saúde a qualidade do atendimento e a segurança do paciente são requisitos mínimos, incluindo o serviço de fisioterapia em âmbito hospitalar que é responsável pela assistência funcional de forma contínua daqueles que necessitam durante o período de internação. Para assegurar a prestação desses cuidados contínuos é necessária uma comunicação efetiva entre esses profissionais (Carmo, 2018 \& Nogueira et al., 2019).

Em um cenário de alto grau de complexidade que é o ambiente hospitalar, um déficit na cultura organizacional pode comprometer o fluxo de informações por uma série de fatores, como por exemplo, profissionais que lidam com longas jornadas de trabalho, pressa em transmitir ou receber informações e registros ilegíveis ou incompletos, gerando um ambiente que fragiliza a segurança do paciente (Farias et al., 2018).

Para a efetividade da comunicação os profissionais precisam reproduzir as informações de forma articulada, nesse sentido, faz-se necessário lançar mão de algumas estratégias, como desenvolvimento de liderança, união dos membros da equipe, adequação sonora do ambiente, olhar direto durante a comunicação, utilização de instrumentos ou protocolos que garantam a transmissão das informações de forma completa e compreensão clara da mensagem (Pedro et al., 2016 \& Moreira et al., 2019). 
O momento crucial para a prática efetiva da comunicação dá-se durante as transferências de cuidados, tanto entre setores, quanto nas passagens de plantões. Falhas nesse processo podem culminar em procedimentos inadequados que não beneficiem o paciente ou até mesmo comprometam sua saúde (Bohrer et al., 2016 \& Oliveira et al., 2017).

A utilização de recursos que auxiliem os profissionais durante a passagem de plantão pode facilitar a transferência das informações, possibilitando a objetividade, assertividade, completude e clareza, por meio de um direcionamento da comunicação, enxugando o processo e evitando esquecimentos sobre a identificação, estado de saúde ou recomendações relacionadas ao cuidado do paciente (Corpolato et al., 2019).

Por isso fez-se necessário a criação de uma ficha de passagem de plantão da equipe de fisioterapia em âmbito de enfermarias e Unidade de Terapia Intensiva do Hospital Universitário da Universidade Federal do Piauí (HU-UFPI), baseada na técnica de comunicação denominada Situation, Background, Assessment, Recommendation (SBAR) que significa situação, breve histórico, avaliação e recomendações para a transferência de cuidados (Burger et al., 2017).

Este estudo tem como principal objetivo avaliar a passagem de plantão fisioterapêutica no Hospital Universitário da Universidade Federal do Piauí (HU-UFPI) e além disso analisar a percepção dos fisioterapeutas sobre a forma como ocorre a passagem de plantão identificando os potenciais eventos que interferem na sua realização.

\section{Metodologia}

Trata-se de um estudo, transversal, prospectivo, exploratório e qualitativo-quantitativo. $\mathrm{O}$ estudo foi realizado nas dependências do Hospital Universitário da Universidade Federal do Piauí (HU-UFPI), na Unidade de Terapia Intensiva (UTI) e nos postos das enfermarias, localizado na cidade de Teresina-PI.

A população foi composta por 30 fisioterapeutas vinculados ao HU-UFPI. Foram utilizados como critérios de inclusão: fisioterapeutas atuantes na assistência direta aos pacientes internados nas enfermarias e UTI do hospital. Os critérios de exclusão foram: profissional afastado da assistência direta ao paciente, por atestado, folga ou férias no período da coleta de dados.

Inicialmente, os participantes foram orientados quanto aos objetivos da pesquisa e que sua participação voluntária ocorreria mediante aceite e assinatura do Termo de Consentimento Livre e Esclarecido.

Foram utilizados os seguintes instrumentos de coleta de dados:

○ Ficha de caracterização da amostra contendo: idade, sexo, estado civil, tempo de formado, tipo de especialização, tempo de atuação no hospital, local de atuação (UTI ou enfermarias), outros empregos e jornada de trabalho.

○ Checklist da passagem de plantão: trata-se de uma investigação sobre os procedimentos e informações que devem ocorrer no momento da passagem de plantão. O conteúdo das perguntas desse instrumento foi elaborado com base no preconizado em protocolos e estudos sobre transferência do cuidado e segurança do paciente, contendo 05 perguntas fechadas, a fim de caracterizar a forma como ocorre passagem de plantão entre estes profissionais. Itens investigados pelo instrumento: 1) Utilizou a ficha impressa na passagem das informações do plantão? - este item pretende averiguar se o profissional utilizou a ficha impressa no momento da passagem de plantão. 2) Verbalizou a identificação do paciente? - neste item a pesquisadora observará se o profissional mencionou o nome completo do paciente. 3) Verbalizou a condição clínica expressa na ficha de passagem de plantão? - neste item a pesquisadora observará se o profissional informou o diagnóstico clínico, nível de consciência, condição respiratória e funcional do paciente. 4) Verbalizou sobre conduta realizada e/ou procedimentos pendentes? - neste item a pesquisadora observará 
se o profissional informou os procedimentos realizados e/ou procedimentos pendentes. 5) Realizou registro completo das informações na ficha de passagem de plantão? - neste item a pesquisadora observará se a ficha de passagem de plantão está preenchida de forma completa e corretamente.

- Entrevista semiestruturada sobre a passagem de plantão: essa entrevista foi conduzida pela pesquisadora e trouxe perguntas abertas sobre a opinião dos fisioterapeutas sobre o momento e o instrumento de passagem de plantão. A entrevista iniciou-se com a pergunta "Qual a sua opinião sobre a passagem de plantão realizada na sua unidade?", e a partir dessa pergunta foram explorados outros aspectos pré-definidos pela pesquisadora como: pontos positivos; pontos negativos e utilização do tempo na passagem de plantão; e potenciais eventos de interferência na realização da passagem de plantão. As respostas das questões abertas foram realizadas verbalmente e gravadas com gravador próprio mediante autorização do participante.

A operacionalização da coleta de dados ocorreu com abordagem inicial ao participante, conforme supracitado, em seguida, foi realizada a aplicação da ficha sobre o perfil da amostra, auto preenchida pelo participante.

Posteriormente, foi feita uma entrevista semiestruturada em local reservado e em horário previamente acordado com os participantes, com seleção de forma aleatória dos profissionais para análise qualitativa da ficha de passagem de plantão, até ocorrer a saturação de resposta, totalizando 10 entrevistas.

A segunda etapa da coleta foi o preenchimento do checklist da passagem de plantão a partir da observação da transferência de cuidados realizada pelos fisioterapeutas de cada setor. Os participantes foram avisados previamente sobre a observação que seria feita pela pesquisadora. Os dados foram coletados durante o período de um mês por três turnos aleatoriamente até que todas as passagens de plantões de todos os profissionais participantes fossem observadas. Analisou-se a transferência de cuidados de três pacientes por profissional, totalizando 69 transferências analisadas.

Os dados quantitativos foram organizados em planilha no programa Microsoft Excel versão 8.0 sendo as variáveis descritas por meio de porcentagem, média, mediana e desvio padrão.

As entrevistas gravadas em dispositivo eletrônico de áudio foram transcritas para o programa de digitação Microsoft Word® e utilizada a técnica de análise de conteúdo baseada na metodologia de Bardin (1979). A análise do conteúdo foi feita para obtenção de grupamentos de temas em categorias para posterior discussão.

O início da pesquisa ocorreu após aprovação da Comissão de Avaliação de Projeto de Pesquisa (CAPP) do HU-UFPI e posteriormente a aprovação do Comitê de Ética em Pesquisa do HU-UFPI obedecendo às normas da resolução 466/12 do Conselho Nacional de Saúde - CNS envolvendo pesquisas em seres humanos.

Todos os participantes foram informados quanto aos procedimentos e a confiabilidade da pesquisa a qual seriam inseridos e, somente, então inclusos no estudo mediante leitura e assinatura do TCLE, que garante aos mesmos o sigilo total da sua identificação assim como o esclarecimento da pesquisa.

\section{Resultados}

O grupo de fisioterapeutas participante desta pesquisa, composto por 23 profissionais, apresentou idade média de $38 \pm$ 5 anos, com média de tempo de formado $13 \pm 5$ anos e tempo médio de atuação em ambiente hospitalar de $7 \pm 3$ anos.

A Tabela 1 apresenta a caracterização da amostra estudada quanto ao gênero, estado civil, local de atuação, quanto à pós-graduação, especialização na área hospitalar, número de empregos e carga-horária. 
Tabela 1. Caracterização de fisioterapeutas atuantes na assistência de pacientes de enfermarias e uti de um hospital público, Teresina, 2020.

\begin{tabular}{|c|c|c|c|}
\hline Variável & & n (23) & $\%$ \\
\hline \multirow[t]{3}{*}{ Gênero } & Feminino & 18 & $78 \%$ \\
\hline & Masculino & 5 & $22 \%$ \\
\hline & Casado (a) & 13 & $57 \%$ \\
\hline \multirow[t]{3}{*}{ Estado Civil } & Solteiro (a) & 5 & $19 \%$ \\
\hline & Divorciado (a) & 2 & $9 \%$ \\
\hline & Viúvo (a) & 1 & $4 \%$ \\
\hline \multirow{2}{*}{ Local de atuação dentro do hospital } & UTI & 13 & $57 \%$ \\
\hline & Enfermaria & 10 & $43 \%$ \\
\hline \multirow[t]{2}{*}{ Pós-graduação } & Sim & 23 & $100 \%$ \\
\hline & Não & 0 & $0 \%$ \\
\hline Especialização em Terapia intensiva e/ou & Sim & 12 & $52 \%$ \\
\hline fisioterapia hospitalar & Não & 11 & $48 \%$ \\
\hline \multirow[t]{3}{*}{$N^{\circ}$ de empregos } & 1 & 5 & $22 \%$ \\
\hline & 2 & 17 & $74 \%$ \\
\hline & 3 & 1 & $4 \%$ \\
\hline \multirow[t]{2}{*}{ Carga-horária } & 30h & 5 & $22 \%$ \\
\hline & $40-60 h$ & 18 & $78 \%$ \\
\hline
\end{tabular}

Fonte: Pesquisa Autoral.

Foram analisadas as transferências de cuidados de 69 pacientes durante as passagens de plantões, sendo observadas três transferências por profissional. (Gráfico 1).

Foi ainda realizada análise qualitativa da percepção dos profissionais quanto à passagem de plantão nos seus setores. Foram feitas 10 entrevistas semiestruturadas divididas em três categorias: opinião do profissional sobre o momento da passagem de plantão (pontos positivos e negativos), potenciais eventos de interferência durante a passagem de plantão e opinião do profissional sobre o instrumento de passagem de plantão (pontos positivos e negativos). 
Gráfico 1. Passagem de plantão fisioterapêutica - análise percetual de transferências de cuidados de 69 pacientes em enfermaria e UTI do HU-UFPI, Teresina, 2020.

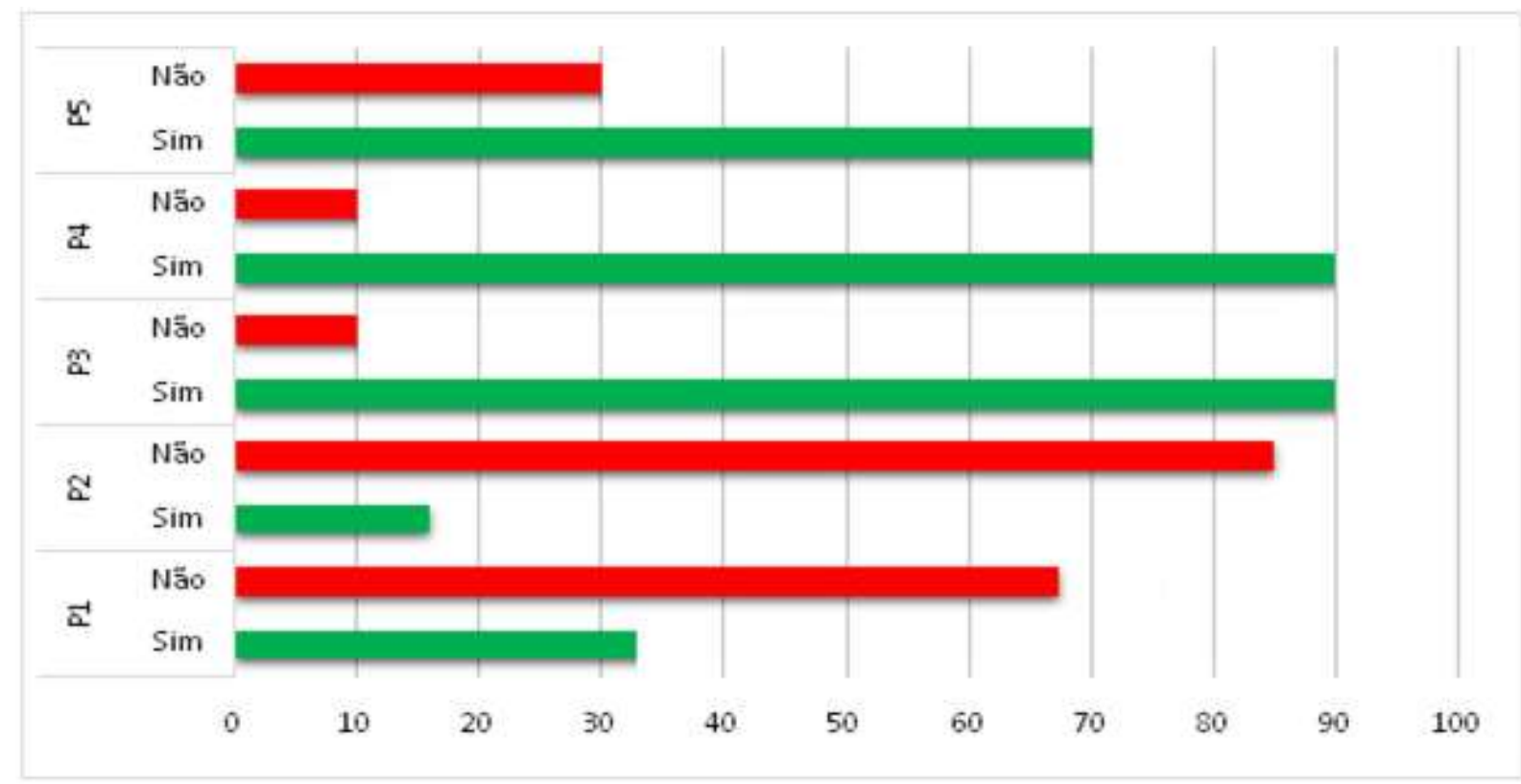

Legenda:

P1: Utilizou a ficha impressa na passagem das informações do plantão?

P2: Realizou a identificação adequada do paciente oralmente?

P3: Informou sobre a condição clínica expressa na ficha de passagem de plantão oralmente?

P4: Informou sobre conduta ou procedimentos realizados oralmente?

P5: Realizou registro completo das informações na ficha de passagem de plantão?

Fonte: Pesquisa Autoral.

\section{Categoria I - Opinião do profissional sobre a passagem de plantão}

- Pontos Positivos:

De forma unânime foi reconhecida a importância da passagem de plantão para a continuidade dos cuidados, tanto no norteamento de condutas, como em estabelecimento de prioridades e planejamento de tratamento.

\section{Entrevista I:}

“... eu acho que a passagem de plantão é extremamente importante porque é a partir dela que o fisioterapeuta, que o profissional já vai iniciar, já vai formular a sua linha de raciocínio para atendimento daquele paciente, além disso, ela é o que dá continuidade no serviço, aonde o que foi realizado e observado pelo colega anterior que está lhe passando o plantão, vai ser fundamental para você dar continuidade e embasar seu próximo atendimento, além disso, você acaba tendo uma visão de tudo que tem sido feito com aquele paciente, o histórico clínico dele."

Entrevista II:

“... a troca de informações, gerando o melhor para o paciente, a discussão de algumas dúvidas sobre a melhor conduta para o paciente na hora da passagem, fora, às vezes, a ficha que gente não coloca, então essa troca de informações e conhecimento é a parte positiva." 


\section{Entrevista VI:}

"Os pontos positivos é que a gente consegue conversar com o colega sobre a proposta de tratamento para os pacientes, passar como os pacientes mais graves, geralmente, estão, então esses são os pontos positivos, traçar uma continuidade de tratamento para aqueles pacientes, conversando com o colega a gente consegue manter mais ou menos a mesma linha de tratamento para eles."

\section{Entrevista X:}

“...o colega já abrevia de certa forma o tempo que você vai passar com o paciente, começa a te fornecer informações bem diretas sobre o paciente e você já vai tomando mais propriedade, além disso, como é algo feito beira leito você já vai dando uma olhada em todo o arsenal que está ali disposto no paciente em termos de bombas, vazão das drogas, as drogas que estão instaladas, a parte respiratória, se está em ventilação ou não, os parâmetros, se o paciente está acordado ou não, você já vai tendo uma visão inicial do panorama do paciente, não que isso vá impedir de você voltar lá novamente quando você for avaliar o paciente, mas você já vai tendo uma ideia, já vai até pré-selecionando quais os pacientes que vão precisar de mais atenção ou não."

\section{- Pontos Negativos}

As maiores queixas concentram-se na ausência de informações sobre o histórico ou condições clínicas dos pacientes durante a passagem ou falta de registros de dados importantes.

\section{Entrevista I:}

“...eu acho que muito a postura da gente profissional de muitas vezes subestimar algumas coisas, tentar simplificar esse momento, que na verdade é um momento muito importante, que como eu falei é o que vai embasar os próximos atendimentos, o próximo plantão, então eu acho que é por conta de pressa, por conta de desleixo, muitas vezes algumas informações são subestimadas e não são repassadas."

\section{Entrevista III}

"Aspecto negativo, eu considero quando algumas dessas informações elas deixam de ser passadas, porque a gente confia bastante pelo que é passado pelo colega, então quando o colega esquece de dizer alguma coisa, isso seria um aspecto negativo."

\section{Entrevista V:}

"O aspecto negativo é que infelizmente não temos o hábito de estarmos com o instrumento de passagem na mão, não fazemos um check-list do que é dito e fica somente a fala e muitas informações ainda podem ser perdidas por isso, pela ausência do hábito de usar o check-list, de estar com o impresso da passagem de plantão na mão.”

\section{Entrevista VII:}

“... a gente percebe que existe uma série de vácuos dentro da passagem que acaba deixando um brecha para que aconteça alguns erros de transferência do paciente no que diz respeito à informações e uma opinião com relação a essa passagem é que essa passagem deveria ser enfatizada sobretudo na transferência dos cuidados na mudança de um setor para o outro, por exemplo, aqui no hospital, a gente foca muito na passagem aqui dentro da UTI, mas esquece que há continuidade lá fora, então acho que deveria ser algo otimizado essa passagem do cuidado e com mais detalhes. Algo que penso, que eu julgo ser 
bem interessante é que às vezes faltam alguns detalhes de preenchimento que fazem a diferença... os objetivos da fisioterapia estão contidos na passagem de plantão, isso é um ponto muito positivo, mas falta um check-list de que objetivos foram atingidos dentro da UTI que objetivos tem como meta para serem atingidos fora do ambiente de terapia intensiva, na continuidade, então a gente tem uma listagem de objetivos que as vezes a gente não atualiza, tem objetivos que, por exemplo, já foram atingidos e continuam lá como objetivo, então é algo que eu acho interessante como ponto positivo, então assim, todos os detalhes são importantes, porém precisam ser complementados e acabo já falando dos negativos, a ausência de parâmetros de mecânica respiratória é um ponto negativo, a ausência de horário de coleta dessas informações de diagnóstico como a hemogasometria é um ponto negativo..."

\section{Categoria II - potenciais eventos de interferência durante a passagem de plantão}

O barulho, conversas paralelas e as intercorrências foram relatados como os principais eventos de interferência que atrapalham as passagens de plantões com maiores frequências.

\section{Entrevista II:}

"A quantidade de profissionais na sala, as vezes as conversas paralelas acabam que dificultam um pouco a passagem do plantão."

Entrevista III:

"Eu acho que às vezes o barulho na UTI, ou quando tem algum outro profissional fazendo a passagem dele também interfere muito, ou as vezes, isso não é muito recorrente, mas às vezes quando acontece atrapalha, é quando um profissional chega atrasado ou outro precisa sair mais cedo ou mais rápido, acho que isso interfere também."

\section{Entrevista V:}

"A maior interferência, sem dúvidas, são conversas aleatórias, assuntos extraordinários ao interesse, conversas, ruidos e barulhos outros."

\section{Entrevista VI:}

"A questão do tempo, geralmente o horário, a gente está saindo e os outros às vezes demoram um pouquinho a chegar, também como tem outros profissionais na sala aí também causa ruídos, as vezes fica muito barulho, porque a gente tenta conversar e os outros profissionais conversam outras coisas, então isso interfere."

\section{Entrevista X:}

"As interferências que a gente costuma ver aqui é que às vezes tem alguma intercorrência com o paciente na hora que você está passando o plantão, aí você tem que parar ali e o colega tem que ficar te esperando e você tem que ir lá socorrer o paciente, também quando tem admissão na hora da passagem de plantão que corta totalmente aquele momento e você tem que parar mais uma vez para ir receber o paciente para poder fornecer para o colega ou até mesmo para ouvir o histórico do paciente e o porquê ele está sendo admitido." 


\section{Categoria III - Opinião do profissional sobre o instrumento de passagem de plantão}

- Pontos Positivos:

Os pontos positivos reconhecidos na passagem foram a capacidade da ficha de compilar informações importantes passíveis de esquecimento durante a transferência dos cuidados e que poderiam se perder ao longo do processo de internação, além da simplicidade e facilidade de preenchimento.

Entrevista I:

"A nossa ficha de passagem de plantão é uma ficha simplificada, ela é facilmente preenchida, ela na verdade de todos os instrumentos foi a que me ajudou, que eu acho que faz diferença você está com ela em mãos na passagem de plantão, até porque ela acumula os eventos que aconteceram com aquele paciente durante a internação dele, fatos que muitas vezes só de cabeça não é lembrado..."

\section{Entrevista II:}

"A documentação, que às vezes a gente pode esquecer alguma informação e tem na ficha, o a parte visual de você ver quantos pacientes foram atendidos, o que foi feito..."

\section{Entrevista V:}

"O instrumento de passagem é um bom instrumento, à medida que os colegas se empenham em coletar todas as informações a que eles se propõem a nos dar, eu acho ele completo, a meu ver ele é completo...”

\section{Entrevista IX:}

"Então a ficha de passagem de plantão consegue resumir bem os aspectos mais relevantes sobre a clínica do paciente, sobre a condição do paciente naquele momento, naquele dia, é uma ficha de fácil preenchimento, manuseio e ajuda muito pra caso que a gente esqueça algo que foi dito pelo colega, a gente vai olhar na ficha e vai estar lá..."

\section{Entrevista X:}

"Em relação também a passagem de plantão escrita, de certa forma é um documento que tem como você resgatar algumas informações, tem como você fixar algumas informações que às vezes a gente não consegue memorizar... ficou bem melhor essa passagem que a gente tem, ficou bem melhor em relação à anterior, porque ela é bem mais objetiva e direta, além de economizar papel, porque antes a gente gastava muitos papéis para isso..."

\section{- Pontos Negativos}

Os pontos negativos relatados não foram direcionados a construção da ficha em si, mas ao programa utilizado para editá-la e a impressão da ficha.

\section{Entrevista I}

“...o que dificulta é que ele tem que ser impresso diariamente, mais de uma vez por dia, duas ou três vezes por dia, o que acaba onerando, dificultando, gerando um resíduo grande..."

\section{Entrevista II:}

"A parte negativa é que às vezes sistema fica um pouco fora do ar, difícil manuseio e aí dificulta na hora de fazer." 


\section{Entrevista VI:}

“...e o ponto negativo que eu acho é sobre o programa em si, o Teams, que geralmente não abre, ontem mesmo eu tentei fazer e eu tive que fazer na ficha antiga, porque simplesmente não abre ou então não copia, é uma confusão, eu acho que o ponto negativo seria esse, o programa em si."

\section{Entrevista IX:}

"Uma coisa que eu acho negativa é apenas o fato de a gente ter que imprimir, porque assim, já tem tanto lixo no mundo, a gente gera muito lixo aqui no hospital e acho que não haveria necessidade de estar imprimindo as fichas, a gente poderia ter acesso pelo aplicativo tanto nos computadores do hospital como pelo celular, hoje tem essa facilidade de ter esse acesso."

\section{Entrevista X:}

"De negativo é o fato de a gente ainda ter que estar imprimindo e carimbando, porque depende muito de disponibilidade de computadores, disponibilidade de papel, quando a gente poderia deixar apenas no sistema com a assinatura eletrônica e outro ponto negativo é que tem muitas informações objetivas, mas praticamente não tem espaço para observações, o espaço é muito pequeno, muito reduzido, então poderia ser aumentado essa parte."

\section{Discussão}

A análise das passagens de plantões fisioterapêuticas realizadas nesta pesquisa constatou que os procedimentos que apresentaram maior adesão foram a verbalização das condições clínicas dos pacientes atendidos e das condutas realizadas e o registro completo das informações no instrumento de passagem. Observou-se menor adesão quanto a identificação adequada (nome completo) e utilização da ficha de passagem no momento da transferência dos cuidados. Todos os fisioterapeutas participantes da pesquisa reconheceram a relevância do momento da transferência dos cuidados e queixaram-se da ausência da verbalização de algumas informações pertinentes e dos barulhos que com frequência interferem esse processo. Também consideraram dispendioso a impressão da ficha de passagem de plantão, no entanto, destacaram a importância do registro das informações no instrumento. Cabe ressaltar que todas as passagens de plantões ocorreram de forma presencial.

Em um estudo sobre o perfil do fisioterapeuta que atua em ambiente hospitalar, verificou que a maioria $(64,4 \%)$, a jornada de trabalho é de 30 horas semanais, o que contrasta com a presente pesquisa que verificou que a maioria possui mais de um emprego, apresentando carga-horária entre 40-60h semanais. Diante disso percebe-se a demanda de tempo que esses profissionais despendem, por isso a necessidade de um instrumento baseado em evidências científicas que otimiza a utilização do tempo durante a passagens de plantões à medida que garante a transmissão de todas as informações realmente relevantes de forma sucinta, minimizando riscos aos pacientes (Nozawa et al., 2008).

A utilização de um instrumento que pauta uma linguagem padronizada, corrobora para a melhoria da assistência. Relatos de profissionais de saúde entrevistados em um estudo, revelaram que a falta de um instrumento norteador torna a transferência de cuidados algo subjetivo e não sistematizado (Soares et al., 2019).

O instrumento de passagem de plantão vigente nos setores alvos deste estudo foi construído baseado no método SBAR (Situação atual; Breve histórico; Avaliação; Recomendações) (Kaiser Permanente Of Colorado, 2017). Contou também com a participação coletiva dos fisioterapeutas e mesmo após a implantação sofreu modificações por meio de consulta/questionários até chegar no melhor formato para a equipe e para o serviço. Além de conter as informações relevantes de forma sucinta, contém também os objetivos e metas terapêuticas que garante a continuidade alinhada da assistência.

Não utilizar a ficha de passagem de plantão pode ocasionar erros como a identificação inadequada ou não identificação do paciente, além de esquecimento de informações sobre a condição clínicas e/ou condutas tomadas (Peruzzi et 
al., 2019). A possibilidade de não memorizar informações importantes e lançar mão da ficha de passagem para assegurar o repasse dessas informações foi algo enfatizado por todos os profissionais entrevistados na presente pesquisa como um dos pontos positivos do instrumento implantado nos setores. Outro ponto positivo apontado foi que esses registros ficam disponíveis em casos de necessidade de acesso no decorrer dos turnos.

No entanto, a maioria dos fisioterapeutas desta pesquisa não utilizou em mãos a ficha de passagem de plantão, mesmo estando preenchida, bem como a maioria também não realizou verbalmente a identificação adequada dos pacientes (nome completo), sendo mencionados apenas o primeiro nome e/ou número do leito. Em outra pesquisa, realizou-se um check-list durante a transferência de cuidados entre enfer meiros do centro cirúrgico e UTI adulto de um hospital escola no município de Goiânia - Goiás, também foi observado um alto percentual na falha de identificação dos pacientes, em 49,3\% das transferência os nomes não foram informados (Bueno et al., 2015).

Apesar de não ter sido observada grande adesão à presença da ficha em mãos durante o ato da passagem de plantão, $\mathrm{o}$ registro completo das informações no instrumento foi constatado em $70 \%$ das passagens de plantões analisadas. Isso pode estar associado à maioria das falas dos profissionais que destacaram dificuldade de impressão da ficha de passagem, por falta de computadores disponíveis, dificuldade de acessar o sistema, além de considerarem as fichas impressas onerosa, como acúmulo de resíduos, enquanto as mesmas poderiam ser acessadas de forma digital por dispositivos móveis durante as passagens.

$\mathrm{O}$ fato de algumas passagens de plantões ocorrerem beira leito pode levar alguns profissionais à subestimarem a identificação adequada dos pacientes ou por considerem o número do leito um identificador adequado, porém, o protocolo de identificação do paciente vigente no serviço pesquisado orienta que o nome completo do paciente, data de nascimento e número do prontuário são os identificadores corretos e nunca o número do quarto/enfermaria/leito em função do risco de trocas no decorrer das internações.

Acerca da opinião de profissionais de saúde sobre o momento da passagem de plantão, assim como em uma pesquisa pesquisa realizada que mostrou que os profissionais consideraram esse um ato relevante em que é possível tirar dúvidas, além de traçar planos de cuidados aos pacientes, sendo esta a primeira linha de comunicação imprescindível da equipe. A respeito deste momento os fisioterapeutas relataram ainda que existem lacunas na verbalização de informações importantes sobre o paciente, isso reflete a ausência física do instrumento de passagem no momento da transferência dos cuidados, uma vez que este propicia a compilação de informações relevantes de modo lacônico (Scrorr et al., 2020).

As maiores queixas dos profissionais de saúde com relação aos potenciais eventos de interferência durante as passagens de plantões apontam para o barulho. Um estudo que avaliou a percepção de 73 profissionais de saúde quanto aos ruídos dentro do ambiente hospitalar constatou que 97,3\% classificou os ruídos de moderado a intenso, 50,7\% se sentem prejudicados pelo barulho e 98,6\% acham que é possível reduzir o nível de ruídos. Esse estudo também utilizou um decibelímetro para realizar mensurações a cada cinco segundos e concluiu que os ruídos encontrados estavam acima dos recomendados (Sampaio Neto et al., 2010).

Em uma pesquisa de abordagem qualitativa, foram evidenciadas três principais dificuldades no processo de passagem de plantão no ambiente hospitalar: o local da passagem de plantão, as interrupções durante este momento, e o volume e excesso de comunicação. A conscientização da própria equipe multiprofissional em resguardar esse momento minimizando os ruídos, principalmente relacionado a conversas paralelas e exacerbação no tom de voz, facilitaria a execução da transferência dos cuidados propiciando a concentração dos profissionais e redução dos riscos de falhas (Nascimento et al., 2018).

Uma limitação apresentada por este estudo foi o acesso a apenas um serviço, uma vez que cada hospital apresenta suas particularidades, rotinas e culturas organizacionais diversificadas. Cabe ressaltar que este é um estudo inédito na literatura na área da fisioterapia, onde foi possível realizar uma análise quantitativa e qualitativa capaz de extrair a percepção dos 
profissionais sobre vantagens e oportunidades de melhorias após a implantação do instrumento e da rotina de passagem de plantão.

\section{Conclusão}

A passagem de plantão fisioterapêutica no serviço avaliado ocorre de forma presencial, a minoria dos profissionais utiliza a ficha de passagem de plantão impressa, bem como a minoria verbaliza o nome completo do paciente no momento da passagem. A maioria expressa de forma verbal as condições clínicas dos pacientes e as condutas realizadas, além de realizarem o registro completo das informações no instrumento.

Os profissionais relataram como pontos negativos do momento da passagem de plantão as interferências causadas pelos ruídos dos setores e consideraram onerosa a impressão do instrumento, entretanto, reconheceram a importância do momento da passagem de plantão para continuidade segura e qualificada dos cuidados, e que a ficha é um instrumento que garante a recordação de informações relevantes dos pacientes.

\section{Referências}

Carmo, C. M. D. (2018). Gestão assistencial da fisioterapia hospitalar: indicadores (Doctoral dissertation, Universidade de São Paulo). https://www.teses.usp.br/teses/disponiveis/5/5170/tde-27022019-150527/en.php.

dos Reis Nogueira, S., de Oliveira Devezas, A. M. L., \& Santos, L. S. C. (2019). Aspectos relevantes na atuação dos profissionais de enfermagem na passagem de plantão. Brazilian Journal of Health Review, 2(4), 2418-2437. doi:10.34119/bjhrv2n4-016.

Farias, E. S., Santos, J. O., \& Góis, R. M. O. (2018). Comunicação efetiva: elo na segurança do paciente no âmbito hospitalar. Caderno de GraduaçãoCiências Biológicas e da Saúde-UNIT-SERGIPE, 4(3), 139-139. https://periodicos.set.edu.br/cadernobiologicas/article/view/5168.

Pedro, D. R. C., Nicola, A. L., \& De Oliveira, J. L. C. (2016). Passagem de plantão entre profissionais de enfermagem hospitalares: análise de fatores influentes. REVISTA UNINGÁ REVIEW, 25(1). http://revista.uninga.br/index.php/uningareviews/article/view/1745.

Moreira, F. T. L. D. S., Callou, R. C. M., Albuquerque, G. A., \& Oliveira, R. M. (2019). Estratégias de comunicação efetiva no gerenciamento de comportamentos destrutivos e promoção da segurança do paciente. Revista Gaúcha de Enfermagem, 40. 10.1590/1983-1447.2019.20180308

de Oliveira ${ }^{1}$, M. C., \& Rocha, R. G. M. (2016). Reflexão acerca da passagem de plantão: implicações na continuidade da assistência de enfermagem. Enfermagem Revista, 19(2), . http://periodicos.pucminas.br/index.php/enfermagemrevista/article/view/13154

Corpolato, RC, Mantovani, MDF, Willig, MH, Andrade, LASD, Mattei, Â. T., \& Arthur, JP (2019). Padronização da passagem de plantão em Unidade de Terapia Intensiva Geral Adulto. Revista Brasileira de Enfermagem, 72, 88-95. 10.1590/0034-7167-2017-0745

Burger, D., Jordan, S., \& Kyriacos, U. (2017). Validação de uma ferramenta de comunicação modificada de alerta precoce vinculada à pontuação, situação, histórico, avaliação e recomendação: Um estudo de métodos mistos. Journal of Clinical Nurses, 26 (17-18), 2794-2806. 10.1111/jocn.13852.

Nozawa, E., Sarmento, G. J., Vega, J. M., Costa, D., Silva, J. E. P., \& Feltrim, M. I. Z. (2008). Perfil de fisioterapeutas brasileiros que atuam em unidades de terapia intensiva. Fisioterapia e pesquisa, 15, 177-182. https://www.scielo.br/j/fp/a/WDsNsLgrsPWCKDNhLPcnrSf/?format=pdf\&lang=pt

de Queiroz Soares, R. A., Miname, F. C. B. R., Mendes, A. F., Ferreira, L. M., Santos, C. M. G., Zecca, A. R., \& Maglioni, S. G. R. (2019). Desafios na construção de um instrumento de passagem de plantão em um hospital de cardiopneumologia. Saúde Coletiva (Barueri), 9(49), 1564-1568. http://revistas.mpmcomunicacao.com.br/index.php/saudecoletiva/article/view/126

Kaiser Permanente of Colorado. (2017). SBAR technique for communication: A situational briefing model. http://www.ihi.org/resources/Pages/Tools/SBARTechniqueforCommunicationASituationalBriefingModel.aspx.

Peruzzi, L. M., Goulart, B. F., Henriques, S. H., Alves, L. R., Laus, A. M., \& Chave, L. D. P. (2019). Passagem de plantão na atenção hospitalar. Rev enferm UFPE on line, 13(4), 989-96. 10.5205/1981-8963-v13i04a236967p989-996-2019

Bueno, B. R. M., de Moraes, S. S., Suzuki, K., Gonçalves, F. A. F., Barreto, R. A. D. S. S., \& Gebrim, C. F. L. (2015). Caracterização da passagem de plantão entre o centro cirúrgico e a unidade de terapia intensiva. Cogitare Enfermagem, 20(3), 512-518. https://www.redalyc.org/pdf/4836/483647680008.pdf

Schorr, V., Sebold, L. F., Santos, J. L. G. D., Nascimento, K. C. D., \& Matos, T. A. (2020). Passagem de plantão em um serviço hospitalar de emergência: perspectivas de uma equipe multiprofissional. Interface-Comunicação, Saúde, Educação, 24, e190119. 10.1590/Interface.190119

Sampaio Neto, R. D. A., Mesquita, F. O. D. S., Paiva Junior, M. D. S., Ramos, F. F., Andrade, F. M. D. D., \& Correia Junior, M. A. D. V. (2010). Ruídos na unidade de terapia intensiva: quantificação e percepção dos profissionais de saúde. Revista Brasileira de Terapia Intensiva,22, 369-374. 10.1590/S0103$507 X 2010000400010$.

Nascimento, J. D. S. G., Rodrigues, R. R., Pires, F. C., \& Gomes, B. F. (2018). Passagem de plantão como ferramenta de gestão parasegurança do paciente. Rev. enferm. UFSM, 1-16. 